\title{
Role of private Sector in Financing of Skill Development in India
}

\author{
Manish Kumar ${ }^{1}$, Dr Nandini Sahay ${ }^{2}$, Dr Saket Bihari ${ }^{3}$ \\ ${ }^{1}$ Phd Scholar, Amity Institute of Social Sciences, Amity University Noida Sector 125, Noida Uttar Pradesh \\ ${ }^{2}$ Asst. Professor (Grade - I), Amity Institute of Social Sciences, Amity University Noida Sector 125, Noida Uttar Pradesh \\ ${ }^{3}$ Associate Professor, Indian Institute of Public Administration New Delhi
}

\begin{abstract}
The advancement in the Third World nations face a few deadlocks. One among these difficulties is low level efficiency and absence of financing from private part for expertise improvement programs. The exemplary inquiries around Labor and skilling strategy discusses are generally about who should direct and pay for the skilling, and what sort of abilities does the workforce need? This paper generally center around the main inquiry on who should lead and pay for preparing and what job private part has in Indian ability advancement framework regarding financing . It is accepted that in creating nations like India where that laborers are generally unfit to put resources into their own aptitudes because of low wages and restricted admittance to preparing, public division is most appropriate to lead the skilling charge however this paper contends that support of private segment as far as financing the skilling program brings viable result for ability advancement programs.

On the side of the contention, a relative investigation of Germany and Japan has been introduced where private division assumes an indispensable part (regarding program plan and financing ) in conferring professional training to the destitute populace. Investigation depends on auxiliary wellsprings of information and broad writing audit of the subject
\end{abstract}

Article Received: 10 August 2020, Revised: 25 October 2020, Accepted: 18 November 2020

\section{Introduction}

The Skill Development Program plans to confer preparing to class and school dropouts, jobless young people, or laborers enjoyed different enterprises, from both provincial and metropolitan territories. The program would assist the common laborers with distinguishing their inclinations and perceive their latent capacity. Then again, Public Financing would go about as an impetus in this worth expansion by giving subsidizing to endeavors, organizations and associations showing up drive to prepare the people.

\section{Objectives of Skill Development}

- To make openings and extension for the advancement of gifts in the adolescent .

- $\quad$ To identify new sectors of skill development.

- To develop employment opportunities.

- $\quad$ To encourage training, support and guidance for occupations where the skill flow is usually through the family member. Such a sect includes carpenter, cobbler, welder, blacksmith, mason, tailor, weaver etc.

- To promote training programmes on the lines of international level. Programmes thus curated would strengthen the youth to cope against the well-set standards of Europe, USA, Japan, Australia, China and Russia.

The Skill Development Programme, though extremely beneficial, faces three major challenges in India.

i) Expanding public sector collaboration with industry and the private sector

ii) Creating pathways for international mobility

iii) women's low participation in the labour force

The potential employer should know the skill of his employees, that would make their willingness to pay more. Recognition of Prior Learning (RPL) is an example of an intervention to address information asymmetry.

Sometimes, the externalities in the industry, when a firm spends resources on developing the skills of an employee, he or she can quit and join another firm, thus benefiting the latter firm and not the firm that incurred the training cost.

\section{Public-Private Partnership in Skill Development: India and other countries}

Though the government of India has created public-private partnerships for the purpose of Skill Development, evidence suggests that so far, only the government has been investing for the cause, rather than a balanced investment, as promised. The role and investment of the private sector in the development programmes is missing.

In a market economy, Public-Private partnership is the glue that links education and employers. Several countries have developed various models to enhance the role of the private sector in skill development. Some of such models are listed below.

- German Model. It has proven difficult to replicate internationally. Some countries, such as Thailand or Korea, have managed to put into place a small number of dual system places.

- Japan Model. Japan has built up its model to expand the inclusion of the private segment in professional instruction and preparing. Despite the fact that this model is totally not the same as the Germany Model, it has its likeness with that in the US and different countries with solid interpersonal organizations . Truly, work for Japan's assembling framework has originated from secondary schools, which have an organization of associations with recruiting administrators that permit them to put their most cultivated understudies specially. This framework depends on a nearby relationship, and relies upon secondary school staff effectively breaking down the abilities of possible alumni and their fit with the scholarly and professional needs of businesses. The Japanese framework is like a degree to what in particular occurs in US professional schools, yet just in those that are high caliber. In the two 
cases, the high quality vocational schools are built of strong relationships between educators and employers.

- Human Resource Development Model/Workforce Development Model. This model spotlights on empowering firm level preparing through government strategy. Nations that have this sort of program incorporate South Korea, Malaysia, and Singapore. They developed in East Asia generally as governments during the 1960s-1980s attempted to fortify monetary development through spending on both introductory and further professional preparing. The center of this HRD procedure are tax assessment strategies that permit the legislature to gather income from firms (normally set at some level of the association's work expenses) and afterward permit firms to utilize these assets to prepare inside their own organizations. In contrast to the customary German arrangement of apprenticeships, this model depends on market systems to build the aptitudes levels of jobless youth, casual division laborers, or officeholder laborers requiring re-tooling.

India reviews the contribution of private sector investment in building the skill ecosystem in the country since many scholars argue that sustainable funding of skill development programs can be achieved through public private partnership because public private partnership brings ownership from private players in the process of delivering skill development programs.

In order to give financing of vocational education, different countries use various methods, although these countries try to keep the things in place, as it helps in connecting individuals, organizations and the State and which ultimately brings benefits to all the three. The role of Vocational education and it's financing for the economy is surely important, but when it comes to its implementation, it is often connected with complications which may be caused due to the socioeconomic and cultural factors of countries. The countries definitely differ in the labour market scale, the quality of teaching and the total amount of financing. All these factors make the countries develop the various models of financing for the vocational education adopted to certain countries. That is the reason, in different countries, the amount as well as the extent of financing may be divided between the private sector and the state.

EU nations are attempting to build up the bound together norm however they are as yet utilizing the various frameworks, as they simply depend on the authentic experience and the homegrown examination, which at last demonstrates the complicacy of financing for professional training.

That is the reason all the nations consistently attempt to make the financing of professional training exceptionally levelheaded and profoundly result-arranged. The referenced can't be given without assurance of work market requests which at last requires efficient control. Because of such oversight, the State will be mindful to decide the requests of the market and their prerequisites, which will permit us to back only the professional divisions and result in the expansion popular. This will likewise advance the spending of assets and will be more viable. Legitimate Analysis of the global practice will likewise bring about the compelling advancement of the ID of the deficiencies in Georgia in this term. Professional instruction is obviously viewed as extremely poor and even it falls behind the worldwide principles.

In the event that we don't decide the normal outcomes, the Rise of financing itself can't be viewed as the progression advances. Reasons, for example, Lack of data and examination keeps us from appropriately arranging the projects of professional proceeding with instruction, in spite of the fact that it requires consideration of the different substances, ex. businesses alongside workers ,hardly any businesses' affiliations and some more.

\section{A case for private Sector involvement in financing of Skill Development}

We clearly know that the private sector along with most of the public sector will only be interested in funding the skill development programmes, only when they are sure about the benefits of skill development towards different sections of the society.

\section{Benefits to Individuals.}

Few of the important private market benefits of education and training are higher wages, improved job and increase in career opportunities, also known as employability. Many studies covering many years from 100 countries with varied differences in culture and economic systems have affirmed the fact that Early education obtained by individuals enhances their personal income.

Research surveyed for the purpose of this found that reskilling, remedial training, on the job training, employer sponsored training have shown mixed success in terms of income for individuals. Some studies have found that labor market training program can raise wages while other have studies have found their impact on wage income to be insignificant. One needs to note that these studies are done to analyse and understand diverse economic, political and cultural system, therefore it's not surprised that results are often mixed.

\section{Benefits to Organisations.}

Many studies have shown that the organizations do inclined to invest in human resource capital since they find their employee performing better and delivering better results. This is even proved with 66 US studies which related training to performance measures, especially operational measures, such as happy and innovative customers. Training tend to increase productivity, but at the same time it also increases the wages .

\section{Benefits to Countries}

There is a strong relationship between human capital and the gross domestic products ( GDP) i.e. The per capita growth of a country.

However, very studies have demonstrated that how varied levels of education, tertiary education, professional education along with the different types of vocational education, play an important role towards the contribution to economic growth. There are no linear graph which demonstrate the robust relationship. It is observed that 
developed economy tend to invest more in human capital. One thing is sure that research on human capital's impact on national economic performance invariably meets the problem that, as skills are very difficult to measure. To achieve higher productivity a country needs all kinds of education i.e. primary, secondary, tertiary and vocational qualifications as well.

Singular type of skill cannot alone be sole reason for generate higher productivity of the country. For example, rise in lower intermediate vocational skills when combined with the rise in upper intermediate skills results in the increased trend productivity in Spain and even in the Netherlands by almost 3.5 to $4 \%$.

In terms of Gross Domestic product growth, estimated effects in similar increases in lower intermediate and higher intermediate skills provided through initial VET are highest in Germany and Spain, with GDP rising by about 1.5 to $2.5 \%$. They are comparatively lower in Sweden and the UK, where output increases by about $0.75 \%$. The increase in Skill also results in decrease of unemployment in all countries.

\section{Survey of Indian \& German firms to demonstrate the importance of private sector in co-creating the sustainable skilling models}

In the essential review ,the technique utilized was a sectoral approach with a particular spotlight on four significant segments - cars, synthetic substances, gadgets, and IT spread across four city bunches of financial (particularly producing) movement in India: Chennai, Bangalore, Pune, and Mumbai.

The overview was directed in three states. 43 firms were reviewed, out of which 12 were German organizations, there were 7 joint endeavors, About 20 were the Indian organizations and the rest were joint organizations with different nations. 32 of the 43 ventures in the example demonstrated that there were more than 100 employed(and consequently were moderately enormous); the staying, under 100 specialists were named as 'little" organizations . As far as areas, 38 organizations were in assembling, while five of them were in administrations. Likewise, out of 38 all out assembling firms studied, 22 were from Auto and auto related firms which represented the biggest offer in the example. Nine were from Electrical and Electronics while around five firms were from the compound part. Specialists viewed the conveyance of firms as far as nature of items (middle products, capital merchandise, and purchaser durables and so forth.), they discovered that the greater part of the organizations were subordinate or in the transitional division, trailed by an equivalent circulation of firms in capital merchandise and buyer durables. A considerable lot of the organizations had a place with the middle part were providers of machine devices, hardware, stopping mechanisms, synthetics and ICT.

Main highlights of the surveys were;

- $\quad 36$ out of 43 firms uncovered that they were confronting a type of aptitude related issues, both in number and the nature of ability they require. On the opposite side Smaller organizations were confronting a significant lack of gifted people. Little firms commonly confronted rivalry of low-end abilities, for example, fitters and circuit repairmen.
Huge organizations confronted the issue of nature of abilities. In any case, given the moderately little size of their example, one can't really sum up across assembling in India. Nonetheless, the idea of preparing given and the accessibility of foundation totally changes as indicated by the size of firms and the quantity of workers. Bigger firms have totally well-prepared instructional hubs, while littler firms need to give practical and work-situated preparing to freshers, in light of their prompt and squeezing expertise prerequisites.

- To meet the ability holes, organizations depended on hands on preparing for newcomers and numerous organizations have an in-house preparing program on processing plant premises. They likewise resort to mechanical changes; at the end of the day, firms supplant work with new machines. Thirty out of 43 organizations overviewed revealed in-house preparing of some depiction; among these 27 are enormous organizations (utilizing in excess of 100 specialists) and the rest 3 little and medium. In-house preparing was being given in every one of the four primary segments overviewed. Out of 22 organizations in the car division, 15 of them were having in-house preparing focuses. electrical and the electronic division shared 9 places, 7 of them had some type of other preparing offices. Them 8 were having preparing offices in compound and IT divisions.

- $\quad$ Twenty seven organizations of the 43 overviewed have demonstrated their enthusiasm for working with different organizations in expertise advancement. As firms were reluctant to share their "exclusive information" barely any organizations needed to joint subsidizing models. Firms were anticipating that the legislature should facilitate among them and think of the model public private help to take care of the expense of preparing. Firms were definitely intrigued to be the piece of such collaboration in the event of some summed up essential preparing. 23 organizations communicated their authentic enthusiasm for working with the legislature as for joint financing; however the little firms then again are hesitant to make any interests in preparing. On the opposite side the Smaller firms were immovably keen on group preparing for ability needs in explicit enterprises. They were anticipating that the administration should play a functioning and significant part in coappointment or building nodal offices to bestow preparing.

- $\quad$ Some firms have demonstrated a craving that the legislature can guarantee a profit for firms speculation on preparing by basically changing guidelines and furthermore by giving motivations to those organizations which give preparing.

- $\quad$ Several endeavors proposed that adjustments in the Apprenticeship Act are important to guarantee the adaptability of compensation and length of preparing.

- Industries and their affiliations ought to be urged to help patch up showing materials, down to earth preparing and word related principles in the light of their expertise needs. Indeed, even before the National Skills Qualification Framework gets obligatory, nearby industry must contribute in the accompanying four different ways:

It offers instructors/mentors from industry to professional school courses and to ITIs to meet the setback of educator/learner who have handy industry experience 
-

The nearby industry must be supported proactively by the focal and state governments to present new courses which addresses the issues of neighborhood industry, and which additionally adds to the planning of an ideal educational program for such courses

- Industries ought to be required, as a feature of its corporate social obligation (as expressed in the new Company Law passed by parliament in 2013), to give temporary jobs to the two understudies of professional training in school just as ITIs

- $\quad$ Based on the utilization of the duality rule, undertakings ought to give guiding to understudies of such professional schools/ITIs in regard of occupation situation. These moves would all be able to be made promptly, without hanging tight for any law. In our essential study we found that while enormous firms have solid budgetary solidarity to direct in-firm preparing however the littler firms don't have a lot of fund to do likewise. Hence, fitting components ought to be created to encourage preparing for littler firms.

- $\quad$ But this is just conceivable when the public part alongside the private segment contributes towards the development and improvement of the nation.

- With the way that the current development pace of populace is 1.4 percent per annum and the Total Fertility Rate falling towards the substitution pace of 2.1 , what is probably going to happen is that the workforce to be gifted would increment however at a declining pattern. The new participants into the work power and the individuals who move occupations would be made out of heterogeneous degrees of abilities, both regarding scale and quality. They all would require changing degrees of skilling and reskilling.

- The need of focused skilling has one more measurement, presently regarding auxiliary change of the economy. As has been featured by Mehrotra et al (2013), there has been an outpouring of work from the horticulture part generally to administrations and assembling in the metropolitan zones. Almost 37 million specialists have just left customary fields of agribusiness between 2004-05 and 2011-12. Right now, just $10 \%$ of the all out workforce has some type of professional preparing. On the off chance that we prohibit the farming area, the extent of laborers having professional preparing would be $20 \%$.

- If we actually reject benefits, the extent would be around 44 percent. The remainder of the workforce should be reskilled so as to spare them from deteriorating in the low paid casual positions in the metropolitan work market. The focal point of preparing along these lines ought to be on advancing abilities appropriate for the sorted out part. Preparing the untalented and semi-talented workforce and making them employable would be the main significant assignment of any legislature.

\section{Conclusion}

Available Evidence suggests that role of private sector in financing of skill development in India is below than expected . So far its only public sector which is funding and steering the skill development. Private sector along with non-profit organizations have been major beneficiaries of gvernment funds.
The large scale picture rose up out of study uncovered that there is solid proof of lack of talented workforce in India's work market. The organizations under examination investigated this ability hole in two different ways: They resort to hands on preparing for the newcomers and a few firms lead in house preparing programs in plant premises, and they change the creation structure and piece of contributions towards capital serious creation. Concerning the previous, the degree of in-firm preparing in India is low among the BRIC nations, for example, Brazil, Russia, India and China . Notwithstanding, reports propose that upwards of 30 firms out of 43 which were reviewed have in house preparing. While enormous organizations have composed preparing plans with tremendous speculations because of accessibility of funds, the littler firms are happy with low degrees of preparing because of absence of money.

In light of above realities, one can draw three significant exercises on how open private association can have effect on livelihood preparing to satisfy the holes of Indian work market.

We comprehended from the review that realize that there is a wide contrast among hypothesis and practice which were clarified by the organizations, transforming the Indian VET has been of most extreme significance, which would be conceivable just when privately owned businesses take an interest in the organization of Indian VET framework. Privately owned businesses have demonstrated their enthusiasm for joining the readiness of educational program, arranging abilities and reasonable preparing and along these lines they can without much of a stretch overcome any barrier among hypothesis and practice.

The private firms are additionally inspired by joint preparing program which likewise remembers joint ventures for preparing. Huge Indian firms have embraced ITIs and has likewise put their funds as far as framework and not many of the preparation offices. Industry Association's essentially CII and FICCI individuals have just embraced a few ITIs and they have likewise communicated their enthusiasm for assuming control over a greater amount of them which would help improve the Indian VET framework regarding both for example the foundation advancement and practicesituated just as the business explicit preparing programs.

Little firms would do well to try different things with different types of preparing plans, for example, group based projects. Firms need a decent ROI when they make interest in preparing.

To sum up, India, at this timeframe is advantaged to have a solid and enormous human asset which no nation would actually have. Be that as it may, her masses are yet to understand their actual potential. It would require a progression of all around oversaw programs in open private organization for diverting their actual potential. Thoughts on co-financing, tax reductions and interest in preparing framework need to reconsidered to make India aptitude capital of the world.

\section{References}

[1] Abuselidze, George and Beridze Lasha.: Financing models of vocational education 
and its impact on the economy: Problems and perspectives, shs web conf. volume 66, 2019 ERPA international congresses on $\quad 2019$. https://doi.org/10.1051/shsconf/201966010 01

[2] Abuselidze, George.,Optimal Fiscal Policy - Factors for the Formation of the Optimal Economic and Social Models. Journal of Business and Economics Review, 3(1), 1827, (2018)

[3] Ashton, D., Green, F.,James, D.,\& Sung, F., Education and Training of Development: The Political Economy of Skill Formation in East Asian Newly Industrialized Economies, Routledge 1999.

[4] Barabasch, Antje, Huang, Sui Lawson, Robert Planned policy transfer: the impact of the German model on Chinese vocational education. Compare: A Journal of Comparative and International Education 2008 Available at http://www.tandfonline.com/loi/ccom20.

[5] Chenoy, Dilp, Aligning Skills with Jobs, Journal of Development Policy and Practice, 2017, Available on https://doi.org/10.1177/245513331667766 2

[6] Gill, Indermit S.; Fluitman, Fred; Dar, Amit [editors]; Gill, Indermit S.*Fluitman, Fred*Dar, Amit [editors]. 2000. Vocational education and training reform : matching skills to markets and budgets (English). Washington, D.C. : The World Bank.

http://documents.worldbank.org/curated/en /306571468750301579/Vocationaleducation-and-training-reform-matchingskills-to-markets-and-budgets

[7] Maclean Rupert, Wilson David, International Handbook of Education for the Changing World of Work, 2009. Springer Science \& Business Media, 2009.

[8] Mehrotra, Santosh, Parida, Jajati, Sinha, Sharmistha, and Gandhi, Ankita "Explaining Employment Trends in the Indian Economy: 1993-94 to 2011-12”,
Economic and Political Weekly, 49(32),2014

[9] Mehrotra Santosh, Raman Ravi, Kumra Neha, Kalaiyarasan, Röß Daniela, Vocational Education and Training Reform in India Business Needs in India and Lessons to be Learned from Germany,2014, http://aei.pitt.edu/id/eprint/74136

[10] Ministry of Science and Education, Report of Reform of Vocational Education, 20172018, Retrieved from: https://mes.gov.ge/content.php?id=8806\&1 ang $=$ geo

[11] MHRD (2011), Working Group Report on Secondary and Vocational Education, 12th Five Year Plan 2012-2017.

[12] MHRD (2011), Working Group Report on Secondary and Vocational Education, 12th Five Year Plan 2012-2017

[13] Ministry of Labour and Employment (2011), “Annual Report 2010-11", Ministry of Labour and Employment, Government of India

[14] Pilz, Matthias (Editor)Preparation for the World of Work", 1 Springer Nature, 2016, DOI :10.1007/978-3-658-08502-5

[15] Takahiko, Karia, Rosenbaum, James, Straetified incentives and Life Course Behavior, in Morimor,J.T \& Shanahan M.J, (Edts) Handbook of Life Course, New York, P-58-71, 2003. Kluwer Academics and Plenum Publishers.

\section{Sources}

[1] https://www.msde.gov.in/nationalskilldeve lopmentagency.html

[2] https://www.bestcurrentaffairs.com/skilldevelopment-initiatives-takengovernment/

[3] Agrawal,Tushar (2012), Vocational education and training in India: challenges, status andlabour 
[4] market outcomes, Journal of Vocational Education and Training, Vol. 64, No. 4, 453-474Mehrotra et al, 2013Computed from the field survey 